\title{
ULTRASONIDO EN TÓRAX PEDIÁTRICO
}

\author{
Ultrasound in pediatric chest
}

\author{
Dr. Aníbal Espinoza G \\ Radiólogo Pediatra \\ Hospital San Borja-Arriarán, Clínica Alemana Santiago
}

\begin{abstract}
ULTRASOUND IN PEDIATRIC CHEST
Ultrasound is a second line technique in the pediatric chest imaging evaluation. In some specific conditions like pleural effusions, diaphragmatic motility and chest injuries, ultrasound provides outstanding and sometimes better information safely and efficiently as it can be performed bedside, usually without sedation and as a non-ionizing radiation alternative. The main pediatric chest ultrasound applications are reviewed and shown in a pictogram assay.
\end{abstract}

Key words: ultrasound, chest, pleural effusion, diaphragm, chest wall, children.

\section{RESUMEN}

Para el estudio del tórax en pediatría, el ultrasonido es una herramienta diagnóstica complementaria. Las ventajas propias de la técnica como ausencia de radiación, la evaluación de la motilidad en tiempo real y alta resolución de estructuras de la pared y espacio pleural, muestran claras ventajas en patologías específicas como el derrame pleural, la motilidad diafragmática y las lesiones de la pared del tórax. Se revisa en una muestra pictográfica las principales indicaciones y utilidad de esta técnica.

Palabras clave: ultrasonido, tórax, derrame pleural, diafragma, pared torácica, niños.

\section{INTRODUCCIÓN}

La radiografía de tórax $(R X)$ es la herramienta fundamental y generalmente la única necesaria para un adecuado diagnóstico en patología torácica pediátrica. En casos complejos es útil la tomografía computada de tórax (TC). La resonancia magnética (RM) aunque sin utilidad práctica actual en parénquima pulmonar es de gran utilidad en patología cardiaca y mediastínica compleja (1).

El ultrasonido en tórax (US) es una herramienta de segundo orden, pero no por eso menos importante, tiene indicaciones precisas donde muestra claramente sus ventajas. Las indicaciones clásicas son la evaluación de los derrames pleurales y la motilidad diafragmática $(1,2)$. En estas condiciones el US entrega la información necesaria y suficiente para una decisión terapéutica, sin necesidad muchas veces de técnicas complementarias.

Las ventajas del US son conocidas: bajo costo, mayor disponibilidad, sin radiación ni necesidad de sedación, capaz de obtener imágenes dinámicas en tiempo real $(1,2)$. Puede ser realizada en forma portátil, muy útil en niños en unidades de cuidados intensivos. La mayor desventaja es ser operador dependiente, necesita de un radiólogo entrenado y de confianza para el médico clínico.

El ultrasonido es incapaz de penetrar estructuras óseas o aéreas, en estos casos solo muestra la superficie de

\author{
Correspondencia: \\ Dr Aníbal Espinoza \\ Hospital San Borja - Arriarán \\ Clínica Alemana \\ Dirección: Dardo Regulez 2341 - Santiago \\ E-mail: anibalespinoza2005@yahoo.com
}

estas. El tórax pediátrico presenta algunas ventajas como: osificación fisiológica incompleta de la caja torácica, timo voluminoso posible de usar como ventana acústica y un menor volumen torácico donde los procesos patológicos contactan la pared con mayor frecuencia; de esta manera se elimina la interfase aérea y es posible evaluar la lesión (3-5).

\section{INDICACIONES}

Las principales indicaciones son el estudio inicial del derrame pleural y de la motilidad diafragmática. Otras indicaciones son: evaluación del timo, lesiones superficiales de la pared del tórax y parénquima pulmonar condensado (1). Revisaremos la utilidad y principales indicaciones de la US en tórax pediátrico, sin incluir la patología cardiaca.

\section{TÉCNICA}

La evaluación de los antecedentes clínicos y radiografías previas es de gran utilidad como elemento de orientación espacial, antes de la realización del US, ya que permite focalizar el estudio. Los transductores a utilizar y sus frecuencias dependerán de la localización de la lesión y su abordaje. Para lesiones superficiales se utilizan transductores lineales de alta frecuencia y menor penetración. Los derrames pleurales se evalúan con transductores de alta y mediana frecuencia. Para abordajes del tórax desde el abdomen, vía subcostal o subxifoidea son útiles los transductores convexos de baja frecuencia y mayor penetración. No es necesario uso de sedación y el examen puede ser realizado en forma portátil (3). 


\section{ESPACIO PLEURAL}

EI US tiene la capacidad de detectar volúmenes pequeños de derrame pleural, significativamente mayor al compararlo con RX. En la práctica clínica los derrames pleurales se presentan generalmente con una RX previa donde es visible la opacidad pleural. El derrame paraneumónico corresponde a la acumulación de liquido pleural adyacente a una infección pulmonar. El US nos permitirá diferenciar si efectivamente existe derrame 0 solo engrosamiento pleural. La magnitud se estima midiendo la distancia entre ambas pleuras. Las características propias del derrame son de gran importancia, pueden determinar manejo terapéutico y predecir la evolución clínica. Las características del líquido pueden ser: sin ecos en suspensión o ser "turbios" y con múltiples tabiques, dependiendo si es un derrame simple o infectado, si contiene pus (empiema), tabiques/ lóculos 0 es un quilotórax (Figura1). Un contenido ecogénico, tabiques y ecos en suspensión son muy sugerentes de empiema. El tiempo de evolución se puede inferir por la presencia de tabiques, los que aparecen gradualmente. Las características descritas de los derrames pleurales son evidentes en la US y escasamente visibles en TC (Figura 2).

Un escenario ideal para la ecografía toráxica es el hemitórax blanco, donde existe desplazamiento o remplazo del parénquima pulmonar (Figura 3). El US es capaz de distinguir entre un derrame masivo, una atelectasia total 0 una masa pulmonar asociada. Al evaluar derrames pleurales no se debe olvidar observar el espacio pericárdico como parte del examen, las neumonías graves pueden presentar derrame pericárdico asociado. Otras causas de derrame pleural son insuficiencia cardiaca congestiva y síndrome nefrótico. El derrame neoplásico es poco frecuente en pediatría $(3,6)$ ( Figura 4)

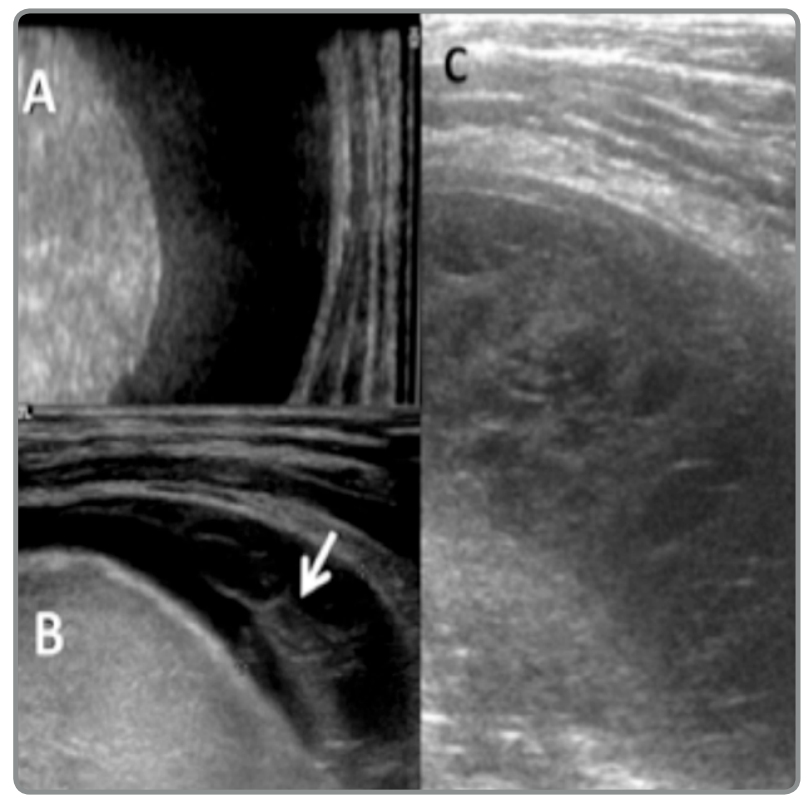

\section{Figura 1.}

A. Derrame pleural con contenido liquido homogéneo, anecogénico, sin tabiques
B. Derrame pleural con tabiques ecogénicos en su espesor (flecha)

C. Derrame pleural ecogénico organizado de aspecto "sólido", que corresponde a empiema

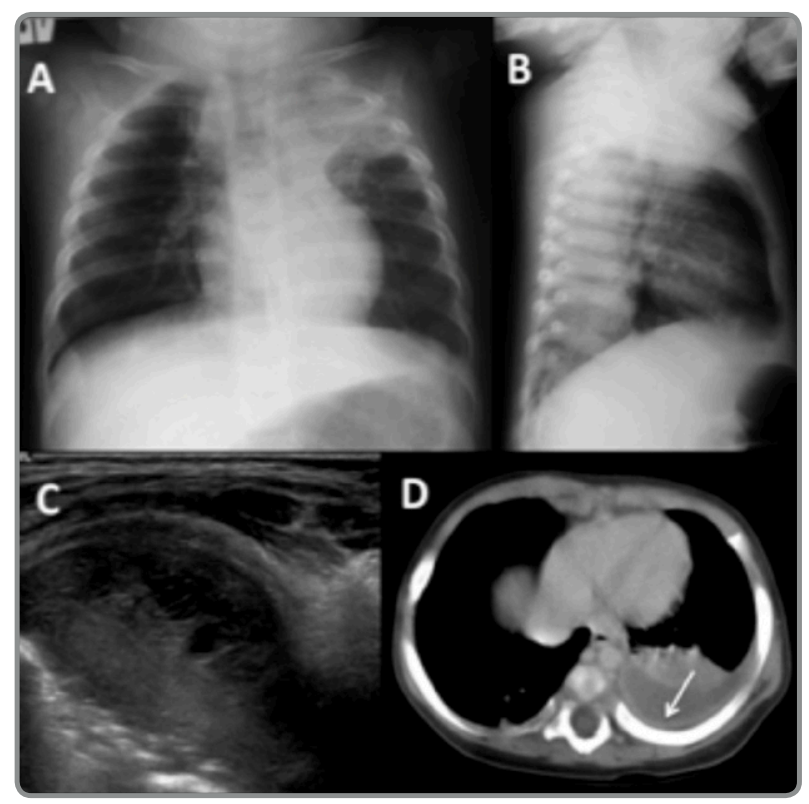

\section{Figura 2.}

A y B Radiografía de tórax muestra densidad parenquimatosa basal posterior y apical izquierda

C. Ecografía demuestra bolsillo pleural basal posterior izquierdo con múltiples tabiques

D. En la Tomografía Computada el derrame se visualiza como liquido homogéneo. Se observa refuerzo hiperdenso post contraste endovenoso de la pleura (flecha), como signo inflamatorio sugerente de empiema 


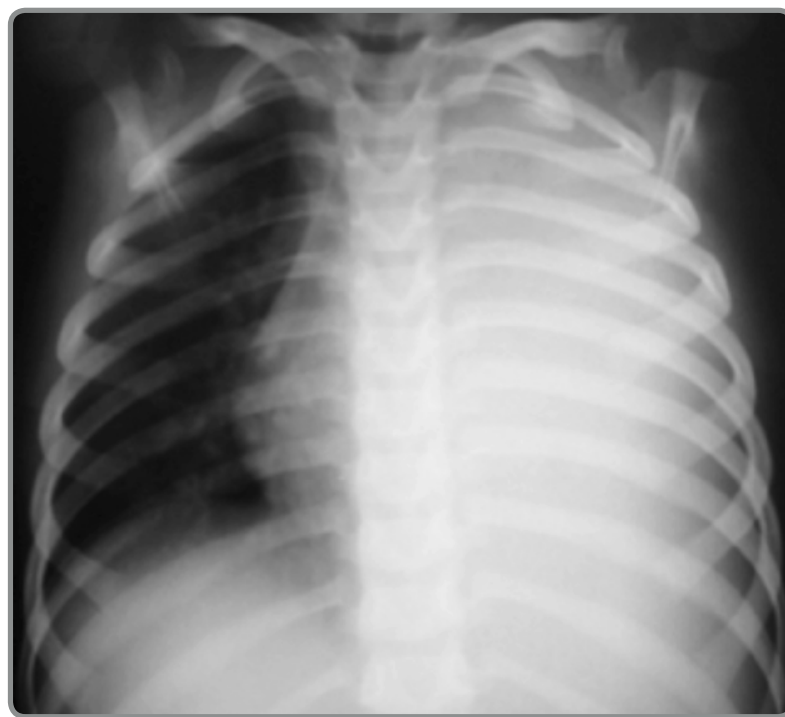

Figura 3.

Hemitórax izquierdo "blanco", sin contenido aéreo. En este escenario la ecografía puede distinguir entre derrame, atelectasia 0 una lesión expansiva.

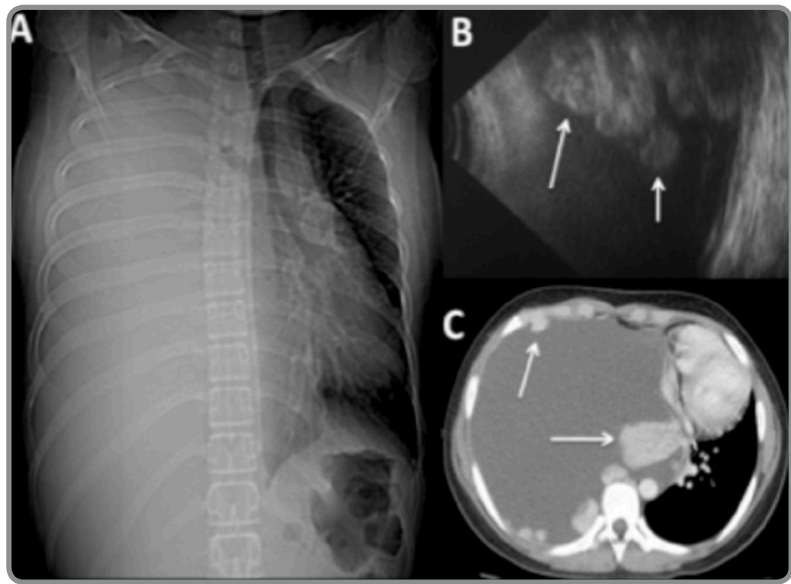

Figura 4.

A. Hemitórax derecho "blanco", con desviación de mediastino a izquierda. Antecedente de Tumor de Wilms derecho operado en tratamiento

B. La ecografía muestra gran derrame pleural con atelectasia pulmonar secundaria, la que presenta múltiples lesiones nodulares en su espesor (flechas), compatibles con lesiones de sustitución secundarias

C. La Tomografía Computada del mismo niño demuestra derrame asociando a metástasis pulmonares y pleurales (flechas)
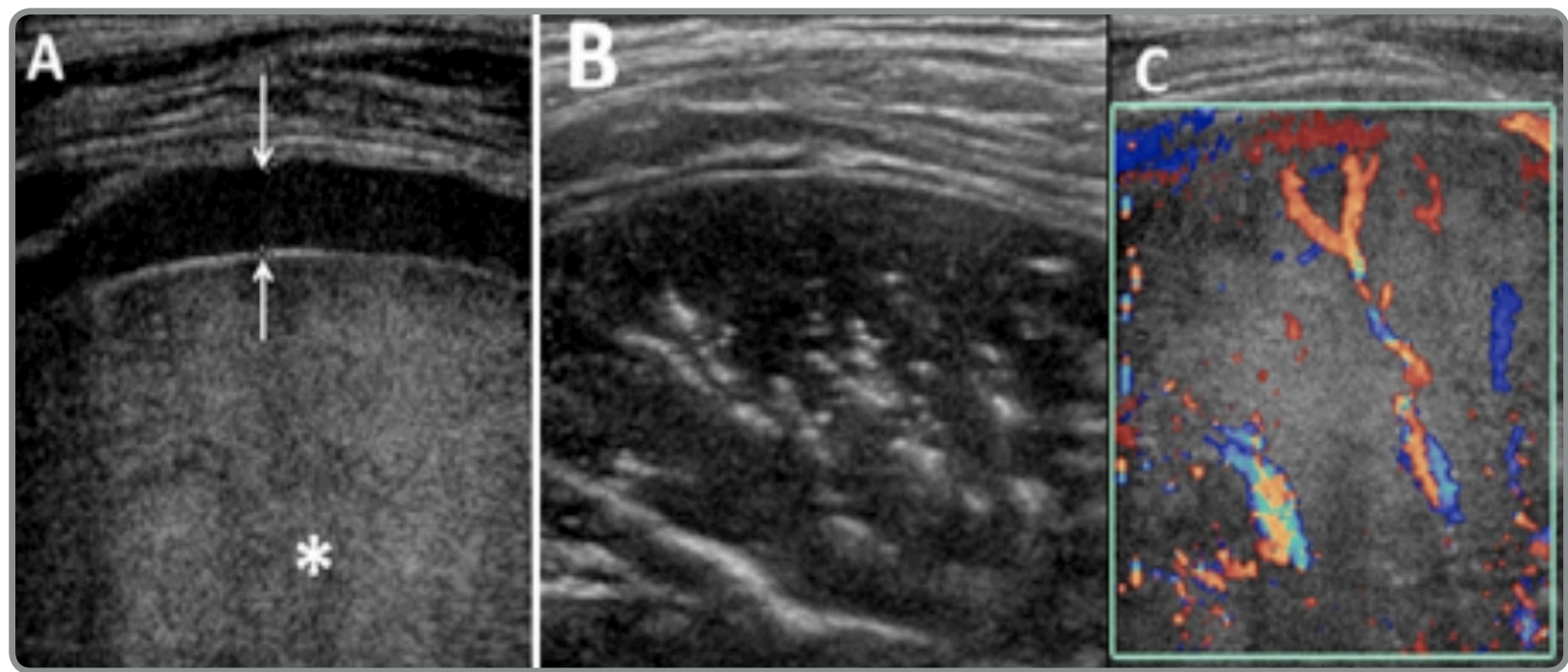

Figura 5.

A. Parénquima pulmonar condensado, homogéneo de aspecto sólido. A este aspecto se denomina pulmón hepatizado(*). Se observa además derrame pleural escaso, marginal, anecogénico (flechas)

B. Parénquima pulmonar condensado con ecos refringentes en su espesor, los que corresponden a aire bronquial (broncograma aéreo ecográfico)

C. Con US Doppler color se visualiza la vascularización pulmonar en el parénquima condensado

\section{PARÉNQUIMA PULMONAR}

El pulmón sano no es evaluable con US pero si el parénquima condensado o pulmón "hepatizado" como se describe en anatomía patológica. Es posible determinar la extensión de la condensación, presencia de broncograma aéreo ecográfico y la vascularización pulmonar con Doppler color
(Figura 5). Un hallazgo importante es la pesquisa de zonas de parénquima condensado con pérdida de la arquitectura normal e hipovascularización al utilizar Doppler color, las que corresponden a necrosis pulmonar focal.

La pesquisa de estas zonas de necrosis parenquimatosa, puede explicar la evolución tórpida de una neumonía y aparición posterior de neumatoceles $(4,6)$ (Figura 6) 


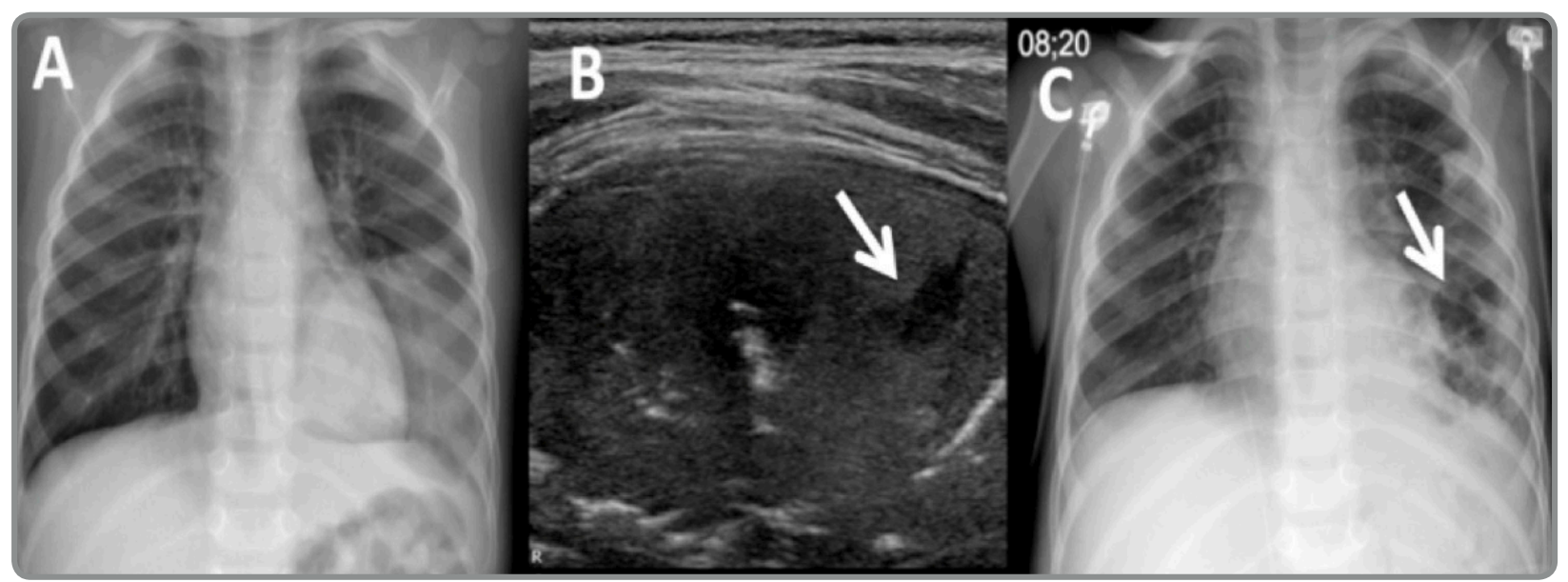

Figura 6.

A. Radiografía de tórax muestra condensación basal posterior izquierda

B. Ecografía de la condensación muestra parénquima heterogéneo con áreas focales hipoecogénicas, las que corresponden a focos de necrosis (flecha)

C. Radiografía de tórax a los 15 días de evolución muestra múltiples neumatoceles flecha)

\section{DIAFRAGMA}

El diafragma corresponde a la estructura músculofibrosa que separa la cavidad torácica de la cavidad abdominal. Al contraerse aumenta el volumen y disminuye la presión de la cavidad torácica. Su inervación proviene de los nervios frénicos. La evaluación anatómica es efectuada con radiografía de tórax , fluoroscopía, ultrasonido, tomografía computada y resonancia magnética. El estudio funcional se realiza con fluoroscopía y ultrasonido evaluando su motilidad (2).

La exploración con fluoroscopia se realiza durante la respiración tranquila y la respiración profunda. Para la evaluación de la excursión se comparan las cúpulas diafragmáticas y el desplazamiento mediastínico. Los signos de parálisis diafragmática son: elevación del hemidiafragma paralizado, movimiento disminuido, ausente o paradojal durante la respiración y bamboleo mediastínico.

El US con respecto a la fluoroscopía tiene como ventajas evaluar el movimiento diafragmático en tiempo real, y posibilitar la visualización de las estructuras por encima y por debajo del diafragma. Los pacientes son examinados en respiración espontánea, con abordaje subcostal y subxifoídeo en línea media. EI US en modo B corresponde a la imagen bidimensional, convencional, permite la visualización morfológica en tiempo real. El modo M o monodimensional, muy usado en ecocardiografía, evalúa el movimiento del diafragma grabado en un punto localizado. Esta técnica evalúa en forma cuantitativa la dirección y amplitud del movimiento de la excursión del diafragma $(2,4)$ (Figuras 7,8 y 9 )

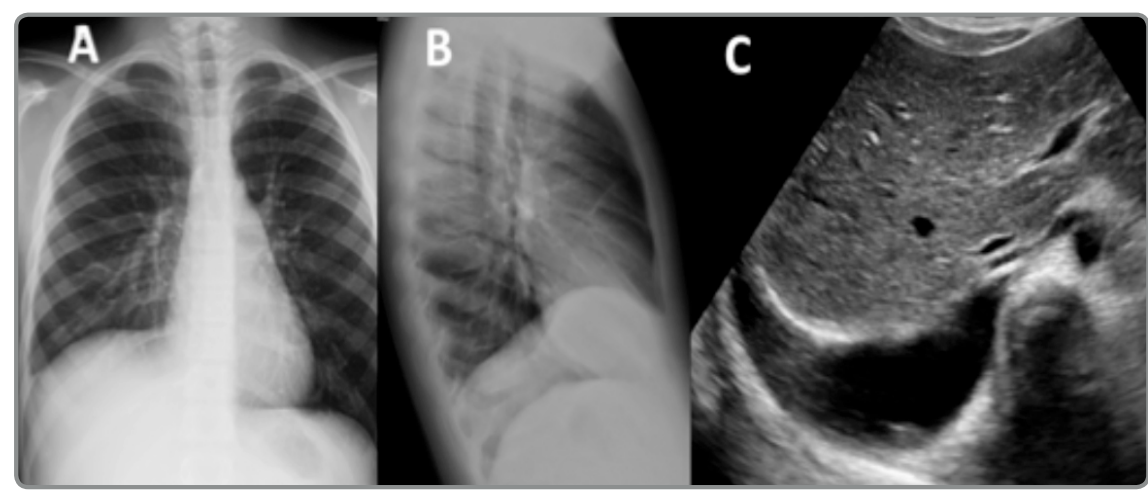

Figura 7.

A y B. Radiografía de tórax, niño de 12 años con dolor toráxico izquierdo leve, sin fiebre. Se observa elevación del hemidiafragma derecho sin ocupación de los recesos costofrénicos lateral ni posterior. Clínicamente se sospecha parálisis diafragmática derecha

C. La ecografia demuestra derrame subpulmonar sin lesión expansiva supra ni intra diafragmática, como tampoco parálisis diafragmática. El estudio posterior determinó la presencia de quilotórax espontáneo 


\section{Figura 8.}

A. Niña de 6 meses de edad operada de tumor rabdoide de pericardio. En radiografía de control se observa elevación del hemidiafragma izquierdo (flecha), que se interpreta como parálisis diafragmática secundaria a lesión frénica izquierda en cirugía previa

B. El Ultrasonido demuestra elevación y parálisis del hemidiafragma izquierdo. Incidentalmente se observa masa sólida subdiafragmática $\left.{ }^{*}{ }^{*}\right)$ no sospechada clínicamente la que también explica elevación diafragmática

C y D. El Ultrasonido modo M de ambos diafragmas muestra a derecha motilidad normal con adecuada amplitud, en el lado izquierdo no se observa motilidad (flecha)

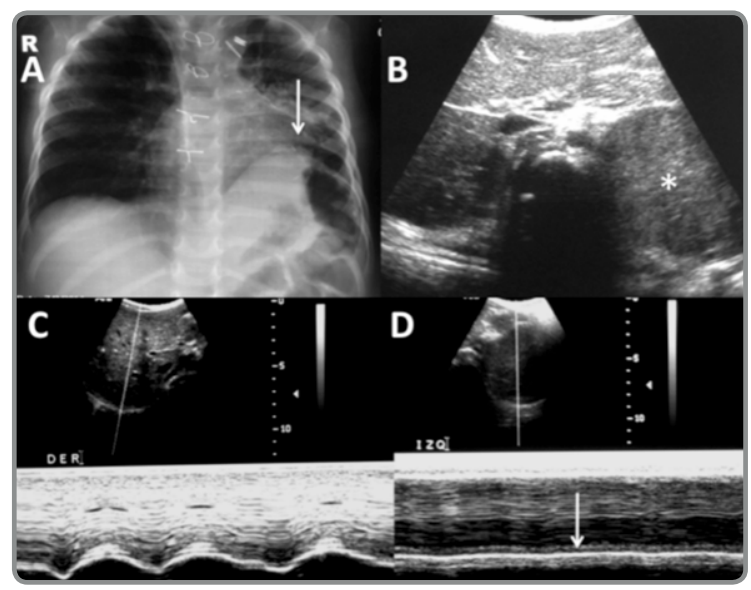

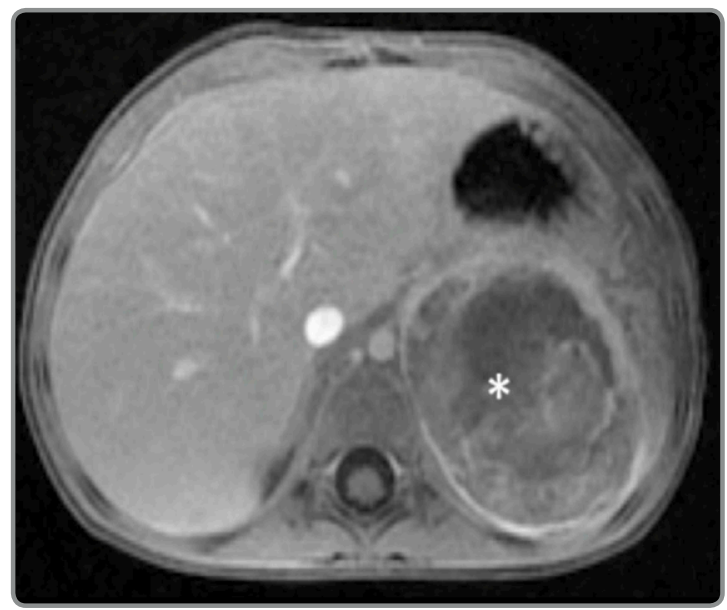

Figura 9.

Resonancia Magnética abdominal confirma lesión expansiva en el región suprarrenal izquierda $\left({ }^{*}\right)$, estudio histológico de la lesión fue similar al tumor primario operado

\section{TIMO Y MEDIASTINO}

El timo en el tórax pediátrico es fácilmente reconocido por radiólogos y clínicos. En la RX el timo puede aparecer de contornos lisos y regulares, pero por su consistencia blanda también puede presentar contornos ondulados secundarios a la impresión por los arcos costales anteriores. Generalmente se proyecta a derecha, pero puede proyectarse a uno 0 a ambos lados del mediastino y presentar una base bien definida horizontal en su borde inferior. Su densidad es de partes blandas y permite la visualización de estructuras vasculares a través suyo. En la $\mathrm{RX}$ en proyección lateral se visualiza normalmente como una opacidad en el mediastino anterior, en la región retroesternal.

Con alguna frecuencia la configuración del timo es inusual y su aspecto puede ser confundido con condensación pulmonar, atelectasias y tumores. En este escenario el US es una herramienta eficaz en identificar el parénquima tímico normal y diferenciarlo de eventuales lesiones. A través del espacio supraesternal y de los espacios intercostales superiores se accede ecográficamente al timo, sin necesidad de sedación, contraste endovenoso ni uso de radiación. El parénquima tímico en US es homogéneo, con finos puntos o septos, hipoecogénico en relación al tiroides adyacente y no comprime estructuras vecinas (Figura 10). Si en la exploración observamos tejido heterogéneo, quistes, calcificaciones o compresión de estructuras vecinas, estamos ante una lesión patológica y serán necesarias imágenes de TC o RM (4) (Figura 11) 


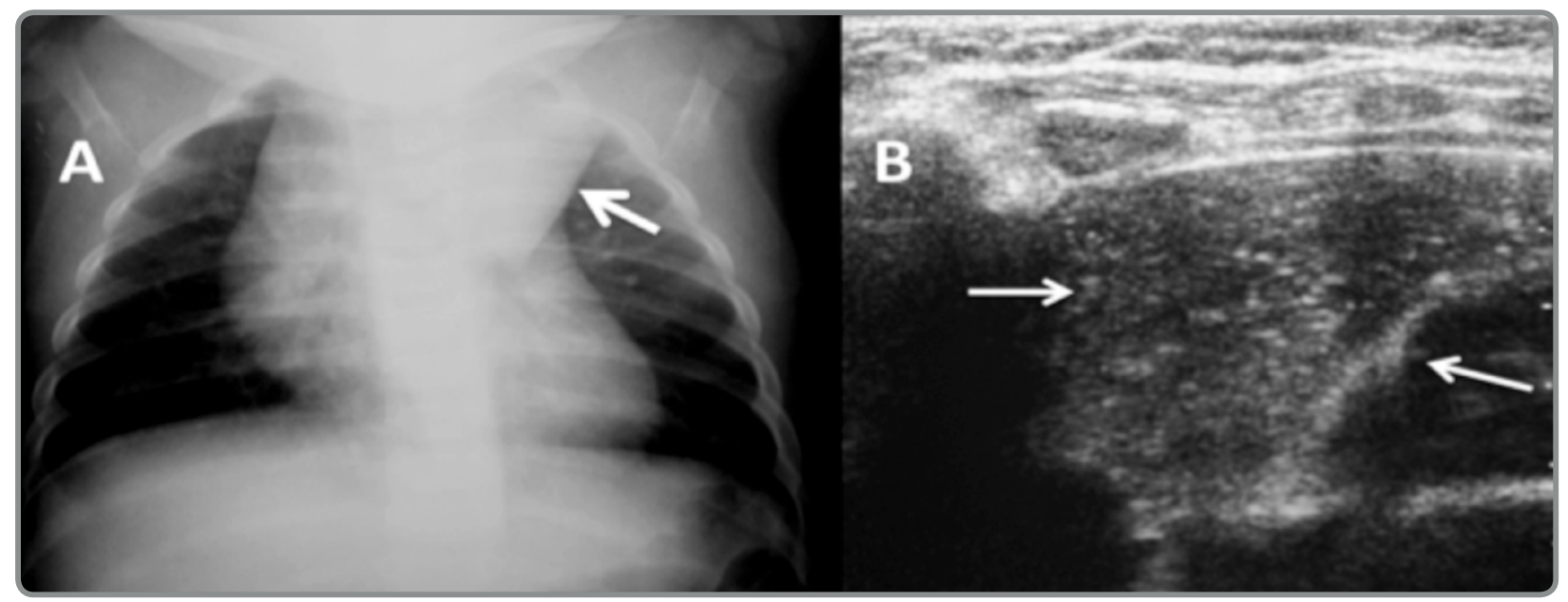

\section{Figura 10.}

A. Radiografía de lactante con un contorno mediastino superior izquierdo inusual, de configuración triangular y borde externo recto (flecha)

B. Ultrasonido con abordaje anterior intercostal izquierdo, se visualiza tejido tímico normal, de aspecto característico (flechas)

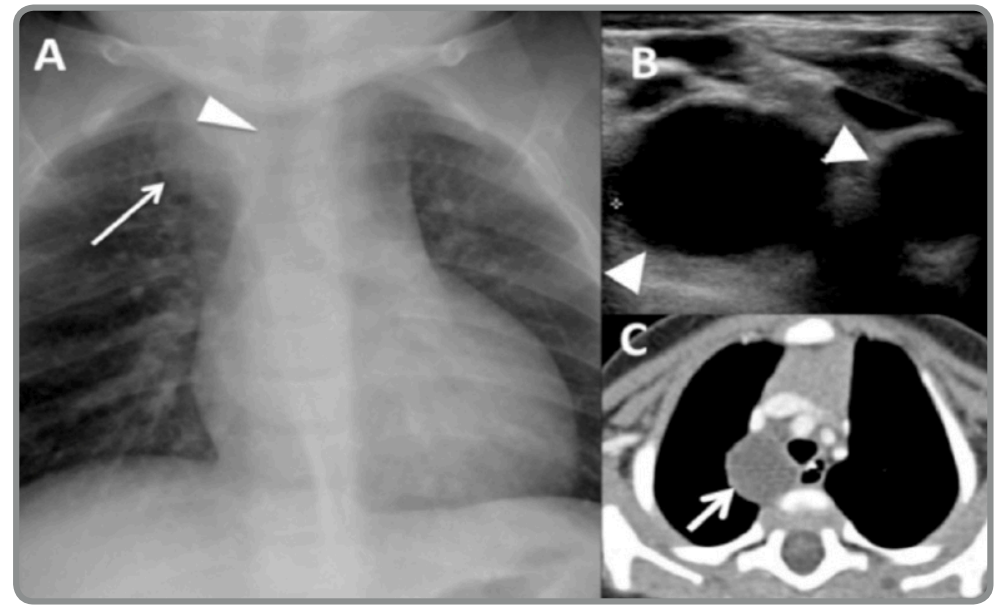

Figura 11

A. Radiografía de tórax de niña de 2 años que muestra aumento de volumen mediastínico derecho por sobre la carina (flecha) con leve desplazamiento de la tráquea a izquierda (cabeza de flecha). Hallazgo incidental.

B. El Ultrasonido demuestra lesión quística simple compatible con quiste broncogénico (cabezas de flechas)

C. La Tomografía Computada muestra quiste mediastínico simple (flecha), en la cirugía posterior se confirma quiste broncogénico

\section{PARED TORÁCICA}

En general las lesiones superficiales en tórax son diagnosticadas correctamente con la inspección clínica y no es necesario apoyo de imágenes. EI US de alta resolución proximal muestra con detalle la dermis e hipodermis, el plano muscular, la superficie convexa de los arcos costales, la configuración cilíndrica de los cartílagos, los músculos intercostales y en profundidad la superficie pleural como una línea ecogénica. Las fracturas costales en pediatría son infrecuentes, cuando no están desplazadas es difícil demostrarlas con RX. Con US Iocalizado, buscando el punto de mayor dolor es posible identificarlas (Figura 12). Es frecuente el hallazgo de deformidades localizadas en costillas o cartílagos costales, fácilmente demostrables con US (Figura 13). Los hemangiomas, malformaciones vasculares y lipomas de la pared son evaluados en su extensión , profundidad y características propias con ayuda del Doppler color. En procesos infecciosos de la pared como celulitis o colecciones permite visualizar la extensión y sirve de guía para drenaje percutáneo. Los tumores malignos primarios o metastáticos son infrecuentes en pediatría, el US puede ser un examen inicial que oriente a su localización, origen, profundidad, destrucción ósea o reacción periostal asociada. Sin duda en estos casos el estudio debe continuar con exámenes como TC o RM $(4,6)$ (Figuras 14, 15 y 16) 


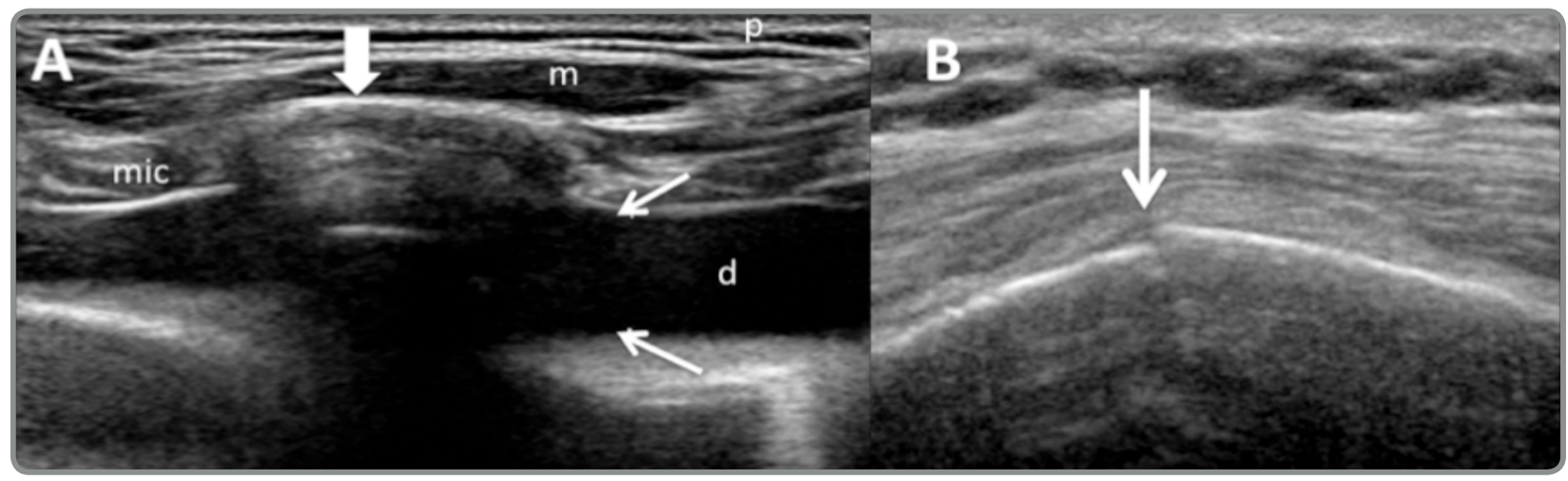

\section{Figura 12.}

A. Con transductores de alta resolución se visualizan: dermis y tejido graso subcutáneo (p), músculos de la pared del tórax (m), músculos intercostales (mic), costilla con cono de sombra acústica posterior (flecha gruesa) y pleuras parietal y vísceral (flechas finas) cuando existe derrame, como en este ejemplo(d)

B. Imagen de fractura costal visualizada como interrupción de la cortical (flecha), visualización longitudinal de la costilla

\section{Figura 13.}

A. Radiografía de tórax muestra aumento de volumen en el cuarto arco costal derecho, extremo anterior, no palpable al examen físico (flecha gruesa)

B. El Ultrasonido visualiza masa sólida bien delimitada, hipoecogénica avascular (Doppler no mostrado), similar al cartílago costal, con las características de encondroma costal (cabeza de flecha)

C. La Tomografía Computada confirma lesión costal de aspecto no agresivo, con extensión fundamentalmente intratoráxica, la que en estudio histológico demostró ser encondroma (flecha fina)

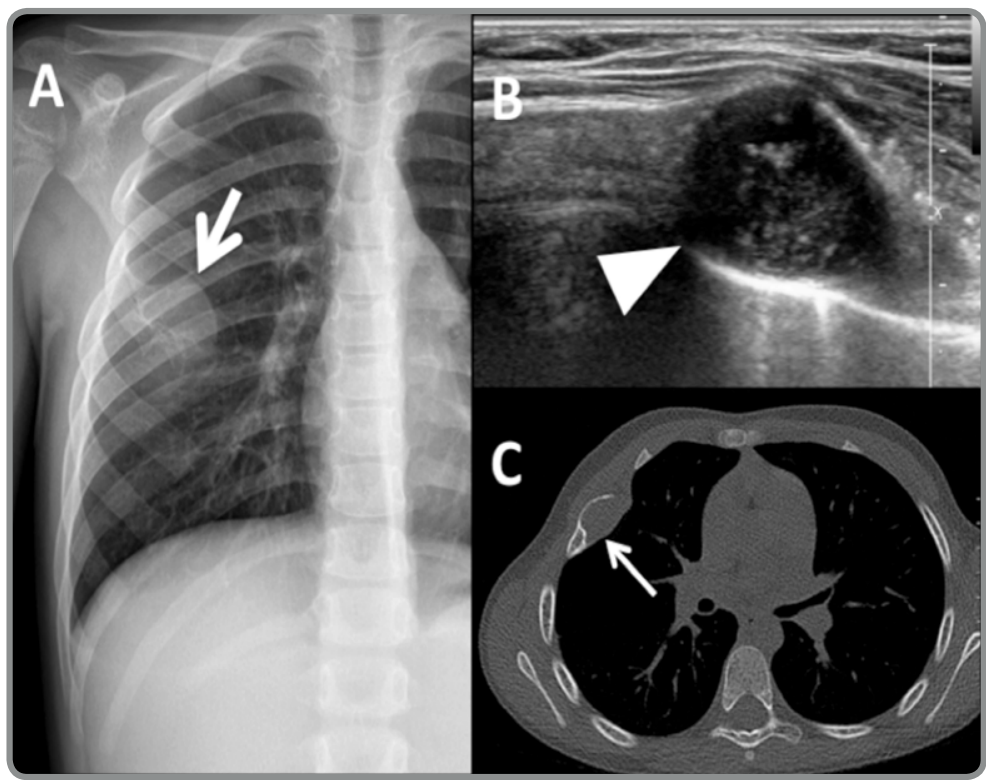




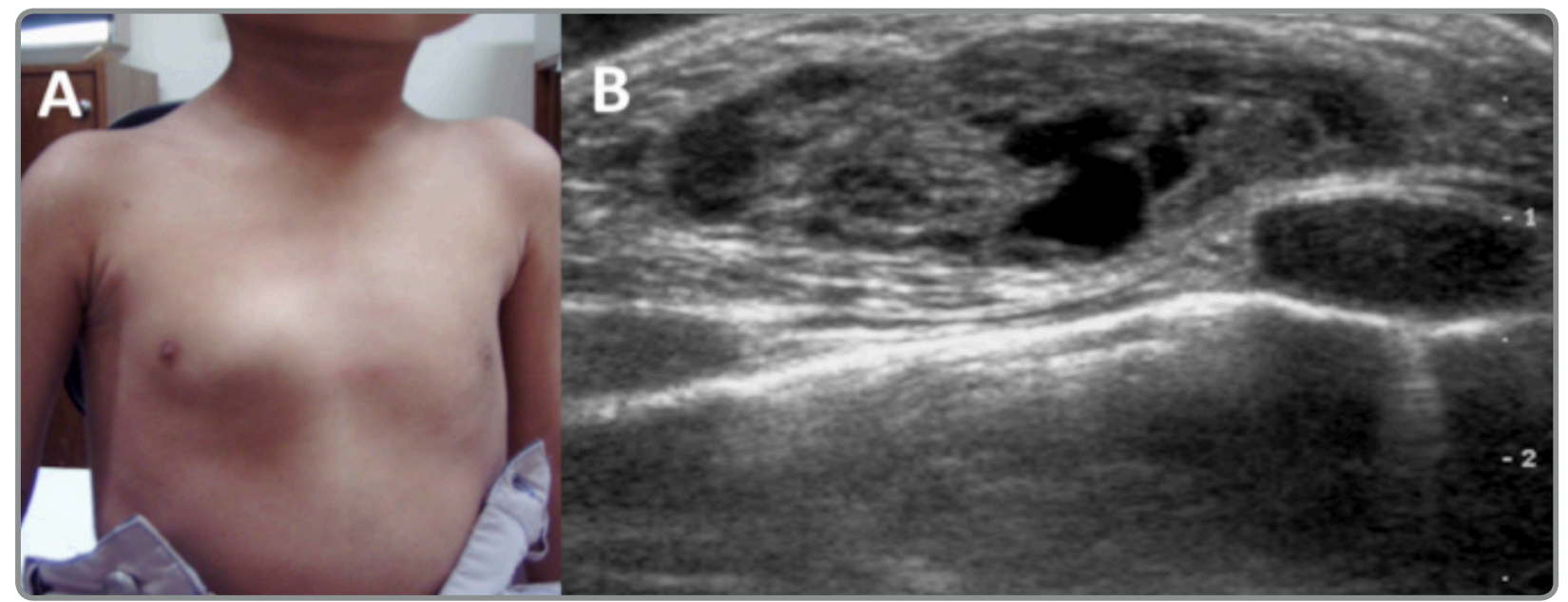

Figura 14.

A. Fotografía de pared anterior del tórax, de niño de 3 años con aumento de volumen paramediano derecho, presente desde el nacimiento, blando no doloroso, sin signos inflamatorios

B. El Ultrasonido muestra lesión expansiva, localizada en el espesor del tejido graso subcutáneo, sólido-quística, con escaso flujo al Doppler color (no mostrado). Las características clínicas y ecográficas corresponden a una malformación vascular de bajo flujo

\section{Figura 15.}

A y B. Radiografía de tórax antero posterior y lateral, muestran neumonía que afecta el lóbulo medio, de evolución prolongada. Durante el tratamiento se pesquisa aumento de volumen en pared toráxica anterior derecha (flecha fina) C. El Ultrasonido visualiza extensión extratoráxica del tejido inflamatorio que compromete el lóbulo medio (flecha gruesa)

D. La Tomografía Computada muestra extensión extratoráxica de proceso inflamatorio pulmonar, que correspondía a neumonía por actinomices

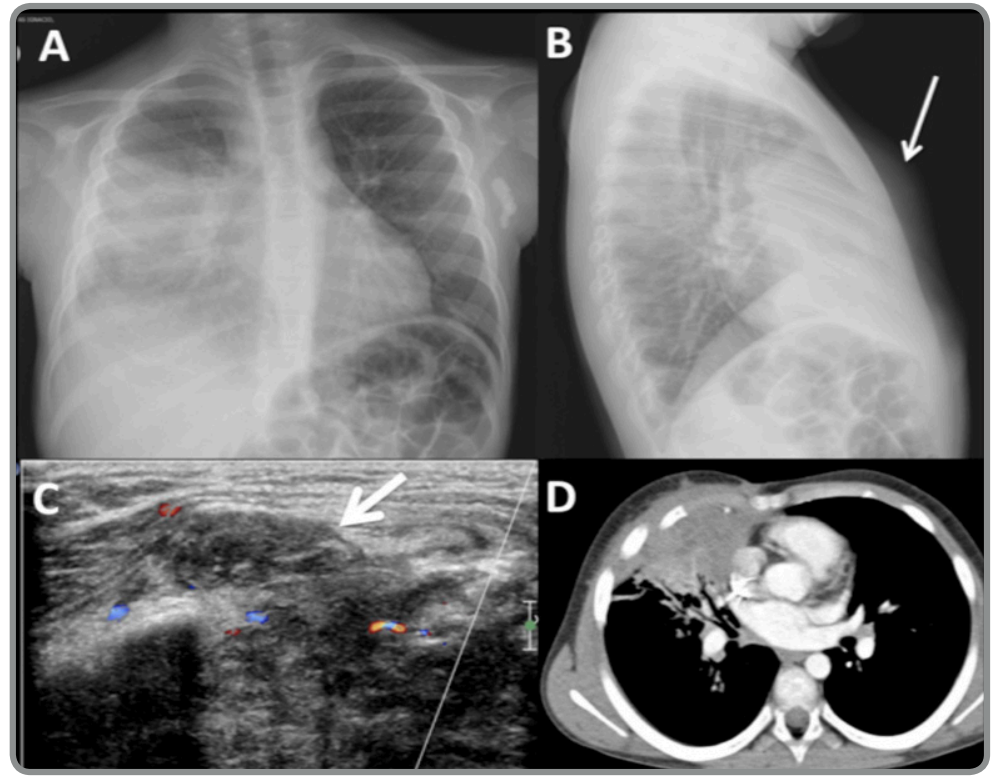




\section{Figura 16.}

Niña de 9 años presenta dolor subagudo y aumento de volumen toráxico dorsal izquierdo. Una Radiografía de tórax inicial no demostró lesión por sobreproyección de estructuras ósea A. El Ultrasonido muestra lesión osteolítica en escápula izquierda, con destrucción del hueso cortical dorsal (cabeza de flecha), matriz sólida, heterogénea y vascularizada al Doppler color (no mostrado)

B y C. Tomografía Computada con reconstrucciones coronal y volumétrica, confirman la lesión ósea escapular destructiva, similar a lo previamente visualizado con Ultrasonido (flechas)

D. RM con uso de contraste endovenoso, demuestra intensa impregnación del contraste en la lesión y tejidos periféricos, compatible con importante fenómeno inflamatorio asociado. El estudio histológico demostró granuloma de células de Langerhans

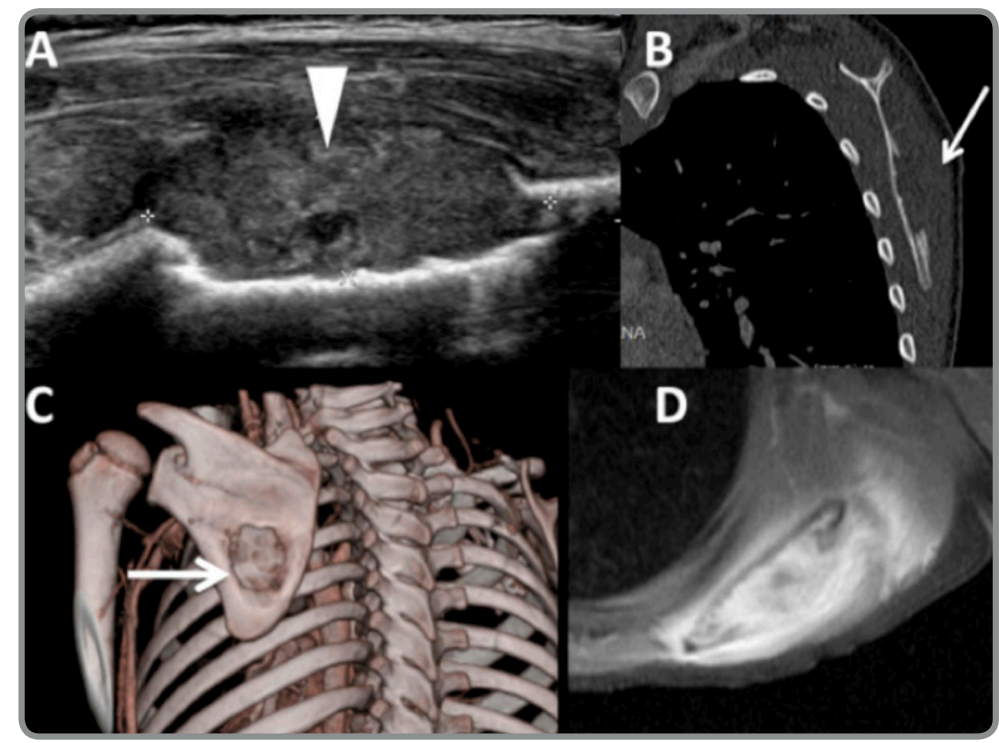

\section{CONCLUSIÓN}

EI US en tórax pediátrico tiene indicaciones precisas donde muestra claramente sus ventajas. Destacan la evaluación del derrame pleural, la motilidad diafragmática y las lesiones de la pared del tórax. En estas condiciones el US entrega información valiosa para una adecuada decisión terapéutica, muchas veces como examen de primera línea, sin necesidad de otras técnicas de imagen.

El autor declara no presentar conflicto de intereses.

\section{REFERENCIAS}

1. Fuentealba I. Ultrasonido de tórax en niños. Rev Chil Enf Respir 2012, 28: 229-235

2. Pérez L. Evaluación por imágenes del diafragma en el niño. Rev Chil Enf Respir 2012, 28: 236-248

3. Kim OH, Kim WS, Kim MJ, Jung JY, Suh JH. US in the diagnosis of pediatric chest disease. Radiographics 2000;20:653-671

4. Coley BD. Chest sonography in children: current indications, techniques and imaging findings. Radiol Clin N Am 2001;49:825846

5. Mong A, Epelman M, Darge K. Ultrasound of the pediatric chest. Pediatr Radiol $2012 ; 42: 287-97$

6. Calder A, Owens CM. Imaging of parapneumonic pleural effusions and empyema in children. Pediatr Radiol 2009;39: 527-537 